\title{
ANTIMICROBIAL ACTIVITY OF IMPREGNATED ANTIBIOTIC MATRIX MATERIALS FOR BONE TISSUE DEFECT RECONSTRUCTION
}

\author{
Andrii V. PANTUS ${ }^{1 凶}$, Mykola M. ROZHKO², Roman V. KUTSYK ${ }^{3}$, Ruslan V. KOZOVYI ${ }^{4}$, \\ Mykola V. MELNICHUK ${ }^{2}$
}

${ }^{1}$ Department of Surgical Dentistry, Ivano-Frankivsk National Medical University, Ivano-Frankivsk, Ukraine

${ }^{2}$ Department of Dentistry, Institute of Postgraduate Education, Ivano-Frankivsk National Medical University, Ivano-Frankivsk, Ukraine

${ }^{3}$ Department of Microbiology, Virology and Immunology, Ivano-Frankivsk National Medical University, Ivano-Frankivsk, Ukraine

${ }^{4}$ Department of Medical biology and Medical genetics, Ivano-Frankivsk National Medical University, Ivano-Frankivsk, Ukraine

Received 12 Jan 2020, Accepted 15 Febr 2020

https://doi.org/10.31688/ABMU.2020.55.1.02

\section{Abstract}

Introduction. Combinations of fibrous materials with therapeutic agents as a drug delivery system are currently studied. A new direction has appeared in reconstructive surgery - tissue engineering, which aims to restore biological functions, i.e. tissue regeneration, not only to replace it with synthetic material.

The objective of the study was to evaluate the antibiotic-sorbing ability of the three-dimensional non-woven matrices we created for reconstructing bone defects, made of polycaprolactone, and the possibility of releasing the impregnated antibiotic from the matrix material.

Materials and methods. The study was conducted in the Department of Surgical Dentistry of Ivano-Frankivsk National Medical University, Ukraine, between September 12, 2019 - October 3, 2019. We used samples of three-dimensional micro-fibrous

\section{Résumé}

Étude de l'activité antimicrobienne des matériaux de matrice imprégnés d'antibiotiques pour la reconstruction des défauts du tissu osseux

Introduction. À ce jour, une nouvelle tendance se poursuit en médecine, qui implique la combinaison de matériaux fibreux avec des agents thérapeutiques tels que les systèmes d'administration de médicaments et les cellules vivantes. À cet égard, la chirurgie reconstructive a formé une nouvelle direction - l'ingénierie tissulaire, qui vise à restaurer les fonctions biologiques, c'est-à-dire à régénérer les tissus, pas seulement à les remplacer par du matériel synthétique.

Objectif. Étudier la capacité d'absorption d'antibiotiques des matrices non tissées tridimensionnelles pour la reconstruction des défauts osseux, créées en 
non-woven matrix for the defects' reconstruction of the bone tissue made of polycaprolactone according to the developed technique. Collagen fragments were used as control.

Results. The evaluation of the preservation of antibiotics in samples of matrix materials was performed on the $1 \mathrm{st}$, $3 \mathrm{rd}$, 5th, 7th, 14th, 18th and 21st day of the experiment. The obtained experimental data indicate that both drugs (cefazolin and lincomycin) were stored in significant quantities both in the collagen and the polycaprolactone matrix, throughout the entire observation period. Lincomycin impregnated in the polymer matrix is less stable during storage than cefazolin. Antibiotics impregnated in the collagen matrix are stored slightly better than when impregnated into polycaprolactone, due to a smaller pore diameter in collagen and, accordingly, a better expressed capillary effect.

Conclusions. The developed matrix materials are a mean of a one-time local delivery of the drug to tissues in the damaged zone. This is especially relevant in surgical dentistry, since even strict adherence to aseptic rules cannot ensure that individual microbial cells from the surface of the oral mucosa and saliva get into the surgery area.

Keywords: matrix materials, collagen, polycaprolactone, impregnation with antibiotics, cefazolin, lincomycin.

\author{
List of abbreviations: \\ CZ - cefazolin \\ $\mathrm{L}$ - lincomycin \\ $\mu \mathrm{g}-$ micrograms \\ EUCAST - European Committee on Antimicrobial \\ Susceptibility Testing \\ rpm - revolutions per minute
}

\section{INTRODUCTION}

Surgical dental interventions for various diseases such as jaw cysts, chronic osteomyelitis and periodontitis often involve the use of additional external structural support to restore bone tissue. Its role is played by a granular framework based on tricalcium phosphate and hydroxyapatite, but a significant problem is the impossibility to restore the bone that is full in structure. In addition, when restoring bone periodontal pockets, granules of osteoplastic material are sometimes disproportionate to the size of small pockets and are unstable in the wound. Microfiber implants made of inert materials polycaprolactone; la possibilité de dégager un antibiotique imprégné du matériau de la matrice.

Matériaux et méthodes. L'étude a été réalisée entre 12 septembre 2019 et 3 octobre 2019 au département de dentisterie chirurgicale de l'Université Nationale de Médecine d'Ivano-Frankivsk, Ukraine. Des modèles de matrices non tissées micro fibreuses tridimensionnelles ont été appliqués pour la reconstruction des défauts osseux fabriqués selon notre technique de polycaprolactone. Des fragments de collagène ont été utilisés comme témoins.

Résultats. L'évaluation de la conservation des antibiotiques dans les échantillons de matériaux de la matrice a été réalisée le 1-er, le 3-ème, le 5-ème, le 7-ème, le 14-ème, le 18-ème et le 21- ème jour de l'expérience. Les données expérimentales obtenues indiquent que les deux médicaments utilisés ( la céfazoline et la lincomycine) ont été stockés en quantités significatives dans les matrices de collagène et de polycaprolactone (Fig. 1) tout au long de la période d'observation. La lincomycine imprégnée dans des matrices polymères est moins stable que la céfazoline pendant le stockage. Les antibiotiques imprégnés dans la matrice de collagène sont un peu mieux stockés que lorsqu'ils sont imprégnés dans polycaprolactone, ce qui est associé à un diamètre de pore plus petit dans le collagène et à un meilleur effet capillaire correspondant.

Conclusions. Les matériaux matriciels développés sont un moyen de livraison locale unique du médicament aux tissus dans la zone endommagée. Cela est une question d'actualité particulièrement en dentisterie chirurgicale, car même le strict respect des règles aseptiques ne peut pas prévenir l'entrée de cellules microbiennes uniques de la surface de la muqueuse buccale et de la salive dans le domaine de la chirurgie.

Mots-clés: matériaux matriciels, collagène, polycaprolactone, imprégnation antibiotique, céfazoline, lincomycine.

can eliminate these physical and mechanical disadvantages of granular material. A new direction has appeared in reconstructive surgery, that includes a combination of fibrous materials with therapeutic agents as a drug delivery system and living cells tissue engineering, with the purpose to restore biological functions, i.e. tissue regeneration, not only to replace it with synthetic material. This approach makes it possible to manage the structural and functional state of the cells involved in regenerative processes ${ }^{1}$.

The development of a functional carrier for cells (matrix) based on biocompatible biodegradable materials is one of the principles of creating 
a tissue-engineering implant. Matrix material performs a complex formative, substitutive, trophic, and inductive role in the implementation of reparative processes. Implants made of biodegradable materials fill the defect of an organ or damaged tissue in a living body and have a therapeutic effect. At certain times, they must undergo biodegradation with the simultaneous replacement with new tissue structures. Natural polymers (hyaluronic acid, collagen, gelatin, fibrinogen, chitosan, pectins, agarose, alginates, cellulose, starch, dextran, matrigel) and synthetic materials (polycaprolactone, polylactide) are considered promising tools for controlled reconstructive tissue restoration ${ }^{2}$.

When creating a tissue-engineering implant, it is important to provide the matrix material with a complex three-dimensional fibrous skeleton structure (non-woven scaffold) with a high surface area to total volume ratio, that simulates an intercellular tissue matrix. Electrospinning is a unique method of forming a porous non-woven matrix. Due to the use of electrostatic forces, it makes it possible to obtain thin fibers from polymer solutions or melts with diameters from nanometers to micrometers, with both a chaotic and oriented fiber arrangement. The three-dimensional implant framework, due to its architectonics and the presence of active functional groups (which is determined by the type of polymer material), promotes adhesion and migration of cells to the area of a tissue defect, provides complex cascades of intercellular signal interactions that underlie angiogenesis, trophicity, and restoration ${ }^{3}$.

Tissue implants are used simultaneously as local delivery systems of antimicrobials (antibiotics, silver sulfadiazine, metal nano-oxides) to the damaged zone in reconstructive surgery of necrotizing infectious processes of soft tissues. Such microfiber materials made by electrospinning have not yet been widely used in surgical dentistry. Electrospinning itself as a method is expensive and power-consuming ${ }^{4-10}$. In addition, in the synthesis of micro- and nanofibers using this method, solvents for polymers toxic to living cells are used. At present, a cheaper and safer method for the synthesis of fibrous matrices and the use of such matrix implants impregnated with antibiotics in surgical dentistry are important.

The obJective OF THE RESEARCH was to study the antibiotic-sorbing ability of the three-dimensional non-woven matrices we created for reconstructing bone defects made of polycaprolactone, and the possibility of releasing the impregnated antibiotic from the matrix material.

\section{Materials AND Methods}

The study was conducted at the Department of Surgical Dentistry of Ivano-Frankivsk National Medical University, Ukraine, between September 12, 2019 - October 3, 2019. In this experimental microbiological study, we used 100 samples of three-dimensional micro-fibrous non-woven matrix for the defects reconstruction of the bone tissue made of polycaprolactone, according to our developed technique.

According to our method, the molten mixture of sucrose and thermoplastic biopolymer was heated at a temperature of $1800^{\circ} \mathrm{C}$, simultaneously centrifuged at a speed of 1500 to $3200 \mathrm{rpm}$. From 3 to 5 minutes after heating and the beginning of centrifugation, the molten mixture of sucrose and thermoplastic biopolymer under the action of centrifugal forces was obtained in the form of thin filaments, which were stretched with cooled air.

At the same time, the diameter of microfibers in the fibrous scaffold we developed reached from 1 to 10 microns. 100 collagen samples were used as a control. The microfiber frame and the collagen pads were divided into fragments and sterilized by g-radiation. The matrix samples were impregnated under aseptic conditions by micropipette application of antibiotic solutions (cefazolin in a final dose of $30 \mu \mathrm{g}$ and lincomycin - $10 \mu \mathrm{g}$ ), followed by drying in a dry oven at a temperature of no more than $30^{\circ} \mathrm{C}$. The dose of antibiotics for impregnation into matrix material samples was set considering the sensitivity of sensory microbial culture to these preparations. Cefazolin (Borschahivskyi CPP, Ukraine) and Lincomycin hydrochloride (Darnytsia Pharmaceutical Company, Ukraine) were used during the study.

All samples were divided into 3 series, which were stored for 3 weeks in different conditions: at room temperature, at room temperature in dark and in the dark in the refrigerator at a temperature of $+4^{\circ} \mathrm{C}$. An additional series of samples with antibiotics introduced into them was not dried and was examined on the 1st day in a wet form. Samples from every series were taken for microbiological studies on the $1 \mathrm{st}, 3 \mathrm{rd}, 5 \mathrm{th}, 7 \mathrm{th}, 14 \mathrm{th}, 18 \mathrm{th}$ and $21 \mathrm{st}$ days of the experiment.

The content of antibiotics in samples of matrix materials and their release into the environment were evaluated by a biological test ${ }^{11}$. As a biosensor, we used a culture of the clinical strain S. aureus sensitive to the indicated antibiotics, identified on the basis of morphological and complex morphological and culture properties, according to the recommendations of the Bergey's Manual, 9th edition ${ }^{12}$ and the biochemical Microtest STAPHYtest 16 (Lachema, Czech Republic). 
The samples selected at the appropriate time were placed on the surface of a nutrient agar pre-seeded with a test culture of S. aureus (standardized by the optical turbidity standard of $5 \times 10^{5} \mathrm{CFU} / \mathrm{ml}$ ). We determined growth inhibition zones of test cultures using the dimer after incubator cultivation at temperature of $37^{\circ} \mathrm{C}$ for 18 hours. We received digital images of the inoculations on the plates, the processing of which was carried out using the UTHSCSA ImageTool 2.0 computer program (The University of Texas Health Science Center in San Antonio, ${ }^{\circ}$ 1995-1996) ${ }^{13}$.

The method of serial dilutions in the broth was used to quantify the release of the antibiotic that was impregnated into the matrix material. The investigation was performed at the following storage periods of samples - the $1^{\text {st }}, 5^{\text {th }}, 7^{\text {th }}, 14^{\text {th }}$ and $21^{\text {st }}$ days. A sample of the matrix with an impregnated antibiotic was placed in a test tube with $2.0 \mathrm{ml}$ of nutrient broth. Antibiotic elution was performed on an MR-1 shaker (SIA BIOSAN, Latvia) at a stirring frequency of 20 times/ min at room temperature for 10 minutes. Next, two serial dilutions of the eluent were prepared in a sterile nutrient broth. $10 \mu \mathrm{l}$ of S. aureus test culture standardized to an optical turbidity standard of $5 \times 10^{7} \mathrm{CFU} /$ $\mathrm{mL}$ were added to all test-tubes. After incubation in a thermostat at a temperature of $37^{\circ} \mathrm{C}$ for 18 hours, the appearance of microorganism growth signs was visually assessed and the experimental value of the minimal inhibitory concentration (MIC) was determined. The ratio of the experimental MIC to the real MIC for the test culture was used to calculate the multiplicity of reducing the dose of the antibiotic released from the matrix sample at different storage periods.

The experimental results were processed by methods of variation statistics and one- and two-factor variance analysis (ANOVA).

\section{Results}

The most accessible and sufficiently sensitive biological test was used to assess the preservation of antibiotics in samples of matrix materials and the possibility of their release in the active state into the environment ${ }^{11}$. A culture of a $S$. aureus clinical strain sensitive to these antibiotics was used as a biosensor. The test strain used in the study was tested for sensitivity to cefazolin and lincomycin, using the disc diffusion method (HiMedia discs, India) and the broth serial dilution method, in accordance with the EUCAST 2019 recommendations (European Committee on Antimicrobial Susceptibility Testing) ${ }^{14}$. The diameters of the growth inhibition zones of the test culture were $29.96 \pm 0.14 \mathrm{~mm}$ for cefazolin (CZ 30 $\mu \mathrm{g}$ ), and $29.60 \pm 0.17 \mathrm{~mm}$ for lincomycin (L $10 \mu \mathrm{g}$ ).

The MIC value for cefazolin - $0.234 \mu \mathrm{g} / \mathrm{ml}$, and lincomycin $-0.039 \mu \mathrm{g} / \mathrm{ml}$ was found using the method of double serial dilutions in the broth. The specified S. aureus strain is highly sensitive to both antimicrobial agents in accordance with the EUCAST 2019 criteria $^{14}$.

According to the results of the S. aureus test strain sensitivity, the final doses of antibiotics for impregnation into the samples of materials were determined. It was found out experimentally that the sorption properties of matrix materials were able to retain without the loss of the water volume that corresponded to their mass $(1: 1, \mathrm{~m} / \mathrm{v})$. Samples of matrix materials were divided into fragments weighing 15.0 mg each, which corresponded to the surface area of standard paper disks for testing antibiotic sensitivity. Antibiotics (cefazolin and lincomycin) were pre-diluted with the sterile isotonic solution for the required working concentrations. Cefazolin was administered at a final dose of $30 \mu \mathrm{g} / \mathrm{sample}$ in the form of a $6 \mu \mathrm{l}$ solution. Lincomycin was administered at a final dose of $10 \mu \mathrm{g} / \mathrm{sample}$ as a solution of $1 \mu \mathrm{l}$.

The content of antibiotics in samples of matrix materials was studied immediately after applying solutions on them and after drying the samples for 60 minutes on the $1^{\text {st }}$ day of the experiment. The drying procedure of the samples (both collagenic and polycapronic) did not at all affect the activity of cefazolin (Table 1).

The activity of lincomycin during the drying process did not change only if the antibiotic was impregnated into the collagen matrix. A slight decrease of lincomycin activity was observed in the polycaprolactone matrix after drying.

Table 1. The content of antibiotics in samples of matrix materials before and after drying procedure (diameters of growth inhibition zones of the test culture of $S$. aureus, $\mathrm{mm}$ )

\begin{tabular}{ccccc}
\hline \multirow{2}{*}{ Antibiotics } & \multicolumn{2}{c}{ Collagen } & \multicolumn{2}{c}{ Polycaprolactone } \\
\cline { 2 - 5 } Cefazolin $30 \mu \mathrm{g}$ & Before drying & After drying & Before drying & After drying \\
\hline Lincomycin $10 \mu \mathrm{g}$ & $28.91 \pm 0.25$ & $29.02 \pm 0.44$ & $27.23 \pm 0.41$ & $27.78 \pm 0.46$ \\
\hline
\end{tabular}

Notes: ${ }^{*}-\mathrm{p}<0.05$ comparing samples before and after drying. 
Evaluation of the preservation of antibiotics in samples of matrix materials was performed on the $1^{\text {st }}, 3^{\text {rd }}, 5^{\text {th }}, 7^{\text {th }}, 14^{\text {th }}, 18^{\text {th }}$ and $21^{\text {st }}$ days of the experiment. The obtained experimental data indicate that both drugs (cefazolin and lincomycin) were stored in significant quantities both in the collagen and polycaprolactone matrix (Fig.1) throughout the entire observation period. This is evidenced by the formation of expressive, comparable in size zones of growth inhibition of the test culture of Staphylococcus aureus.

The antimicrobial activity of cefazolin impregnated samples of the polycaprolactone matrix had

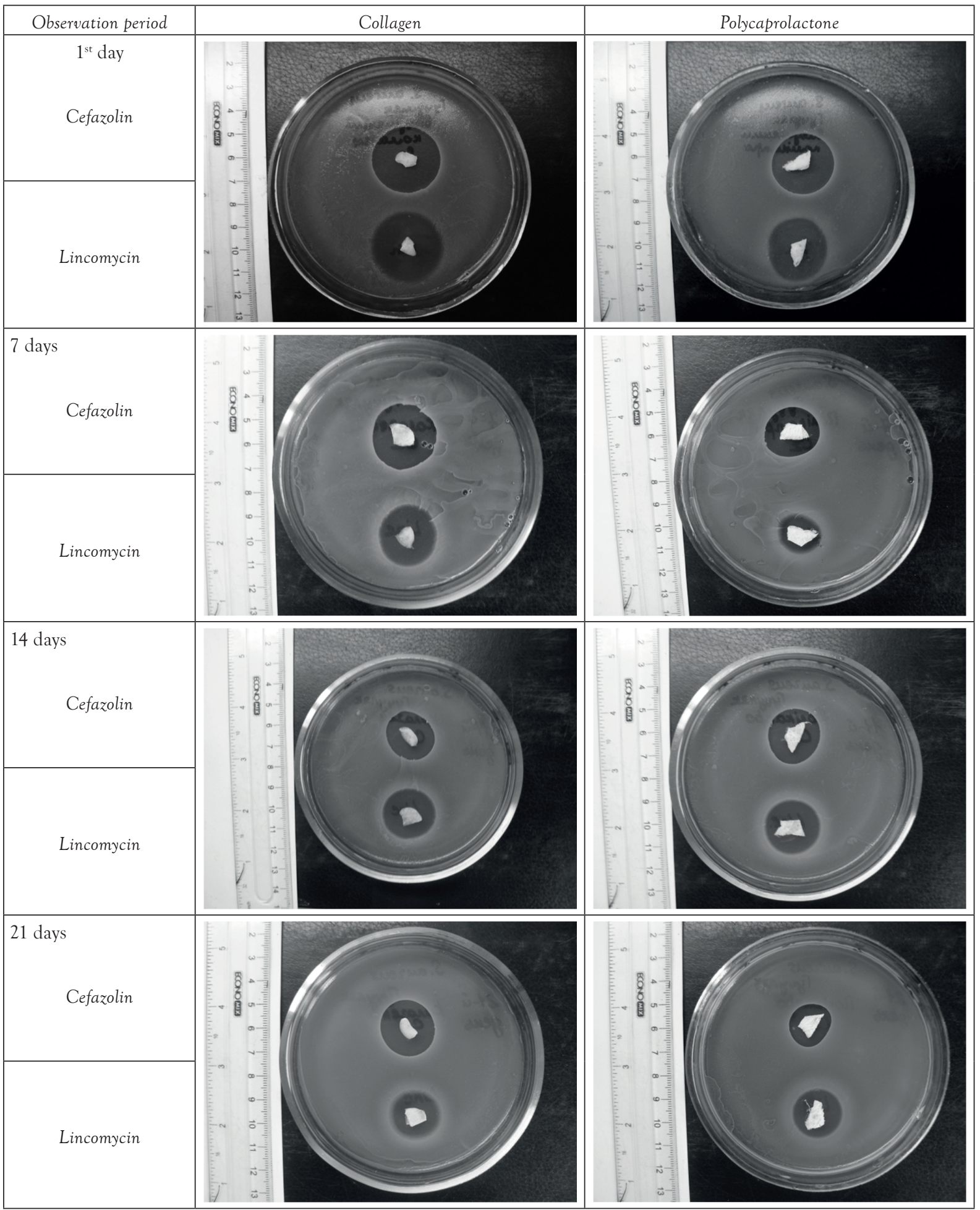

Fig.1. The content of antibiotics in samples of matrix materials at different terms of their preservation at room temperature. 
Table 2. One-factor dispersion analysis (ANOVA) of impact of the storage time of matrix materials samples on the antimicrobial activity of the antibiotics impregnated in them.

\begin{tabular}{cccc}
\hline Investigated samples & Fisher's criteria F & p-value & F critical \\
\hline Collagen + Cefazolin & 26.57417 & 0.000239 & 4.747225 \\
\hline Polycaprolactone + Cefazolin & 18.75035 & 0.000978 & 4.747225 \\
\hline Collagen + Lincomycin & 19.66946 & 0.000814 & 4.747225 \\
\hline Polycaprolactone + Lincomycin & 12.81067 & 0.003788 & 4.747225 \\
\hline
\end{tabular}

been maintained at the initial level for 3 days, collagen matrix - for 5 days. The activity of impregnated cefazolin decreased by $9.0 \%(\mathrm{p}<0.05)$, on polycaprolactone $-16.4 \%(p<0.05)$ after 7 -day storage at room temperature on the collagen matrix. The decrease in the activity of cefazolin impregnated in the collagen matrix continued until the $14^{\text {th }}$ day of observation (it reached $20.7 \%, \mathrm{p}<0.01$ ), but stopped in case of the sample longer-term storage (on the $18^{\text {th }}-21^{\text {st }}$ days). The progressive decrease in the activity of cefazolin impregnated in the polycaprolactone matrix was observed at the same time. At the end of the observation period (after 21 days of storage), the diameter of the growth delay zone of the test culture decreased by $35.2 \%(\mathrm{p}<0.01)$.

The antimicrobial activity of lincomycin-impregnated matrix samples decreased during storage at a faster rate. The diameters of the growth inhibition zones of the $S$. aureus test culture around collagen matrix samples decreased by $21.4 \%$, and polycaprolactone $-39.8 \%(p<0.01)$ on the $7^{\text {th }}$ day of observation. The progressive decrease in the activity of lincomycin impregnated in the collagen matrix continued until the end of the observation period (21 days) and reached $37.6 \%(\mathrm{p}<0.01)$.

The impact of the storage time of matrix materials samples on the antimicrobial activity of the antibiotics impregnated in them was confirmed during the statistical processing of the experimental data obtained by the method of one-factor dispersion analysis (ANOVA) (Table 2). The impregnated antibiotics activity decrease during storage for 3 weeks was statistically significant for all investigated samples of matrix materials.

A more accurate method that allows to determine the concentration of the antibiotic in the test sample is the method of serial dilutions in the broth. This method also allows evaluating the release of the antibiotic that was impregnated in the matrix material into the surrounding liquid medium. The multiplicity of reducing the dose of the antibiotic released from the sample matrix at different periods of its storage was evaluated in the course of the study (Fig. 2).
A decrease in the concentration of lincomycin impregnated in the polycaprolactone matrix was the most pronounced during storage. After 1-5 days of storage, it decreased by 8 times, and after 7-14 days - by 16 times in relation to the initial level ( $F$ $\left.=27.0938 ; \mathrm{F}>\mathrm{F}_{\text {crit. }}=5.3177 ; \mathrm{p}=0.0008\right)$ in the eluent of the respective samples. The concentration of cefazolin impregnated into the polycaprolactone matrix also significantly decreased $\left(\mathrm{F}=7.5000 ; \mathrm{F}>\mathrm{F}_{\text {cri }}\right.$ $=5.3177, p=0.0255)$, but at a less rapid pace: within 14 days of storage, no more than 4 times, after 21 days -8 times. The collagen matrix showed the ability to retain impregnated antibiotics more efficiently than a polycaprolactone one. However, the activity of lincomycin impregnated into collagen also significantly decreased over time $\left(\mathrm{F}=8.8889 ; \mathrm{F}>\mathrm{F}_{\text {crit. }}\right.$ $=5.3177 ; p=0.0176)$, especially after storing samples for $7-14$ days -8 times. The greatest stability during the storage was shown by collagen matrix samples with impregnated cefazolin, that is consistent with the results obtained at agar-gel diffusion studies. The concentration of cefazolin in the eluent of collagen matrix samples remained unchanged at the initial level during the entire observation period. In this case, no significant effect of storage time on the antibiotic activity was found $(\mathrm{F}=1.0000 ; \mathrm{F}<\mathrm{F}$ crit. =5.3177; $\mathrm{p}=0.3466$ ).

Thus, it can be concluded that lincomycin impregnated into polymer matrices is characterized by less stability than cefazolin during the storage. Antibiotics impregnated in the collagen matrix are stored slightly better than when impregnated into polycaprolactone, that is due to a smaller pore diameter in collagen and, accordingly, a better expressed capillary effect. However, the concentration of antibiotic that was held on polycaprolactone matrix was quite enough for an obvious antimicrobial effect in the initial stages of tissue regeneration. The concentration of antibiotics in the eluent of the test samples was as close as possible to the control values during storage of impregnated matrix materials for a period of no more than 5 days. 


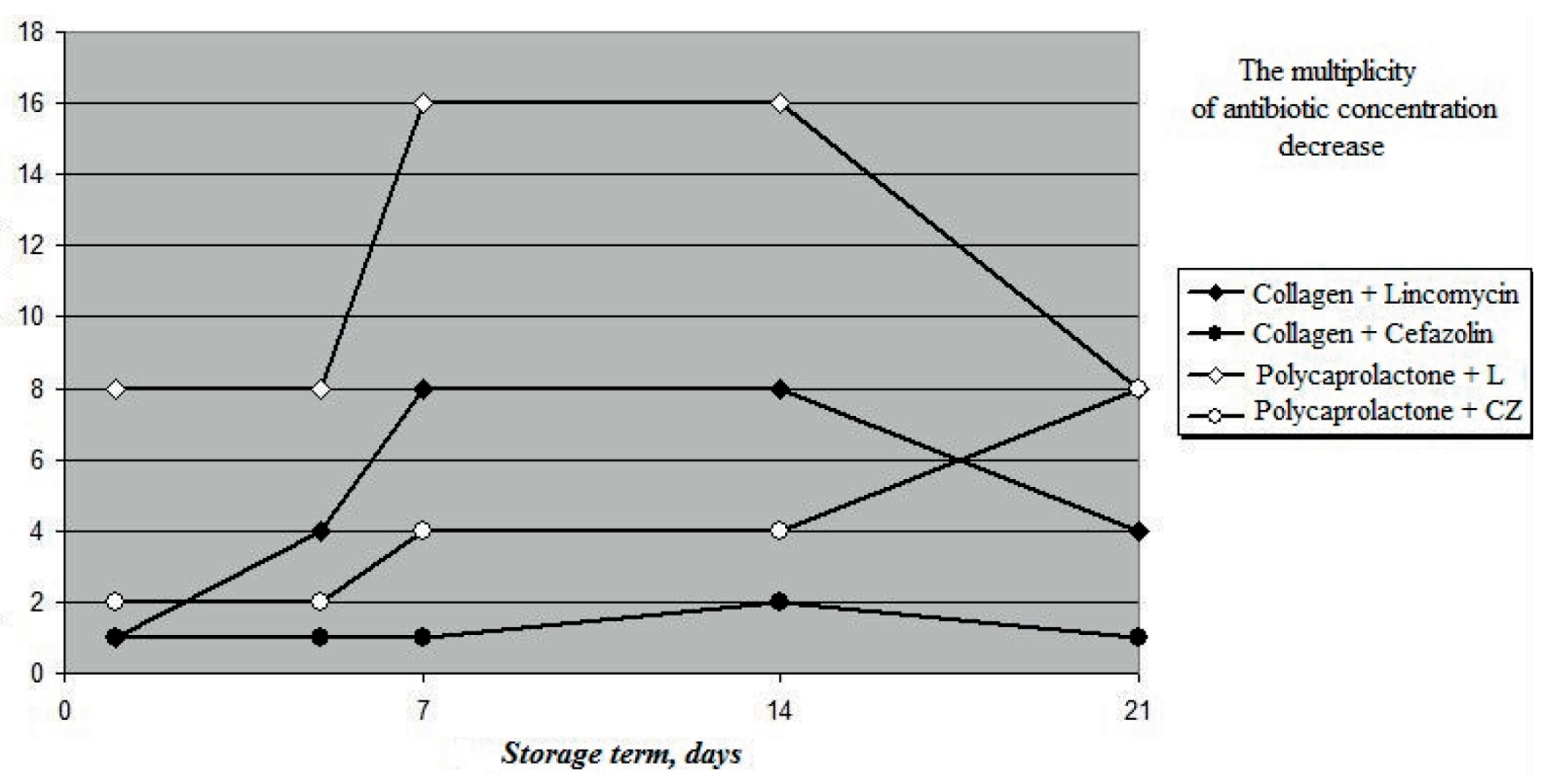

Fig. 2. The multiplicity of antibiotic concentration decreases in the eluent of the studied matrices after different periods of their storage at room temperature

The method described by us made it possible to evaluate the release of an antibiotic impregnated into a sample in the gel medium. It occurs as a result of the antibiotic transition to the soluble phase under conditions of adequate humidity and subsequent diffusion into the agarose gel. This process simulates the events that occur after matrix implantation in the tissue and saturation of its tissue fluid. According to the diffusion law, the impregnated drug enters the surrounding tissues. However, the antibiotic elution stops quite quickly due to the rapid decrease in the concentration gradient. Its duration depends on the antibiotic dose impregnated in the matrix material. Clarification of this issue may be the subject of additional experimental research.

Thus, the developed matrix materials are a mean of a one-time local delivery of the drug to tissues in the damage zone. Related to the above considerations, it is possible to predict their greatest effectiveness in terms of prevention of postoperative infectious complications. This is especially relevant in surgical dentistry, since even strict adherence to aseptic rules cannot ensure that individual microbial cells from the surface of the oral mucosa and saliva get into the surgery area. Immediate contact of microbial cells with an antibiotic eluted from the implanted matrix leads to their immediate death and makes it impossible to express their invasive potential. The pathogenic and opportunistic pathogenic oral microflora is mainly represented by streptococci, staphylococci and actinomycetes, characterized by high sensitivity to cephalosporins and lincosamides (which led to the choice of antimicrobials for this development).

\section{Discussion}

Collagen and fibrin are known to have potential use as a local drug-delivery system ${ }^{15,16}$. In experimental study, authors evaluated a fibrinogen-based collagen (FBC) fleece, coated with thrombin and aprotinin, that can be used as an antibiotic delivery system ${ }^{9}$. In an in vitro study, gentamicin, fosfomycin, ampicillin, ciprofloxacin and dibekacin were absorbed by the FBC, Kirby-Bauer disks (KBDs), and expanded polytetrafluoroethylene ${ }^{9}$. After washing with saline or phosphate buffer saline (PBS) 3 times for 6, 12 and $24 \mathrm{~h}$, each sample was analyzed for antibiotic retention. In an in vivo study, the authors implanted the FBC onto mouse livers and dripped gentamicin and ciprofloxacin onto the $\mathrm{FBC}^{9}$. The FBCs were subsequently collected and analyzed for their antibiotic activities. After PBS washing, the $\mathrm{FBC}$ impregnated with each antibiotic had higher activity than the KBDs, and inhibited the bacterial growth by $60-80 \%$ compared to the control ${ }^{17}$. Gentamicin dripped onto the FBC could inhibit bacterial growth after $48 \mathrm{~h}$ in vivo, without affecting the hemostatic properties of the $\mathrm{FBC}^{17,18}$. Some bases, including FBC, can retain antibacterial activities depending on the ingredients of the base and the type of antibiotic. Gentamicin, but not ciprofloxacin, was retained in the $\mathrm{FBC}$ in vivo. These results suggest that absorbent $\mathrm{FBC}$ might be useful 
not only as hemostatic material, but also as a local drug-delivery system ${ }^{9,17}$.

Resorbable poly-L-lactic acid (PLLA) cylinders (3.5 $\mathrm{mm}$ diameter, $5 \mathrm{~mm}$ in length) carrying $6 \%$ of weight ciprofloxacin (Ciprobay, Bayer AG, Leverkusen, FRG) were investigated in vitro, to explore their properties as a slow-release antibiotic deposit. For comparison, a gentamicin-polymethylmethacrylate (PMMA) chain (Septopal, E. Merck, Darmstadt, FRG) was exposed to similar test conditions. The concentrations of ciprofloxacin released were analysed by a microbiological method (bioassay). The concentrations of ciprofloxacin released from 40 cyclinder were initially very high (up to $180 \mathrm{mg} / \mathrm{L}$ ), but they decreased rapidly within the first 5 days $(4.2-22.5 \mathrm{mg} / \mathrm{L})$. Early release of gentamicin reached up to $227.5 \mathrm{mg} / \mathrm{L}$, but dropped to of $22 \mathrm{mg} / \mathrm{L}$ on the $14^{\text {th }}$ day?

Further research may be directed at the clinical efficiency of implants from developed matrix materials impregnated with antibiotics. The elution time of impregnated antibiotics from different matrix materials requires clarification. The development and study of new matrix materials capable of providing a sustained release of antibiotics into tissues in the area of their infectious lesions may be a long-term research issue.

\section{Conclusions}

Lincomycin impregnated in the polymer matrix is less stable during storage than cefazolin. Antibiotics impregnated in the collagen matrix are held better than when impregnated into polycaprolactone. The concentration of antibiotics in the eluent of the studied samples of matrix materials at the level of control values is maintained for a period of not more than 5 days.

\section{Authors contributions}

Conceptualization, A.V.P. and M.M.R.; methodology, R.V.K.; software, A.V.P. and M.V.M.; validation, M.M.R. and R.V.K.; formal analysis, M.M.R.; investigation, A.V.P. and R.V.K.; resources, M.M.R. and R.V.K.; data curation, M.M.R.; writing - original draft preparation, A.V.P.; writing - review and editing, M.M.R., R.V.K., M.V.M.; visualization, A.V.P. and R.V.K.; supervision, M.M.R.; project administration, M.M.R. All the authors have read and agreed with the final version of the article.

\section{Compliance with Ethics Requirements:}

„The authors declare no conflict of interest regarding this article"

„The authors declare that all the procedures and experiments of this study respect the ethical standards in the
Helsinki Declaration of 1975, as revised in 2008(5), as well as the national law"

"No funding for this study"

Acknowledgments: none

\section{References}

1. Sharma A, Faubion WA, Dietz AB. Regenerative materials for surgical Reconstruction: current spectrum of materials and a proposed method for classification. Mayo Clin Proc. 2019;94(10):2099-2116.

2. Khotimchenko YuS, Shcheblyikina AV, Kumeiko VV. Biocompatible matrix implants from natural and synthetic polymers as promising products intended for treatment of degenerative and post-injury diseases of central nervous system. Pacific Medical Journal. 2012; 2: 54-60.

3. Conway J, Jacquemet G. Cell matrix adhesion in cell migration. Essays in Biochemistry. 2019;63(5):EBC20190012.

4. Markakis K, Faris AR, Sharaf H, Barzo Faris, Rees S, Bowling FL. Local antibiotic delivery systems: current and future applications for diabetic foot infections. Int J Lower Extremity Wounds. 2018;17(1):14-21.

5. Marson BA, Deshmukh SR, Grindlay DJC, Ollivere BJ, Scammell BE. A systematic review of local antibiotic devices used to improve wound healing following the surgical management of foot infections in diabetics. Bone Joint Journal. 2008;100-B(11):1409-1415.

6. Garvin K, Feschuk C. Polylactide-polyglycolide antibiotic implants. Clin Orthop Relat Res. 2005;437:105-110.

7. Teupe C, Meffert R, Winckler S, Ritzerfeld W, Törmälä P, Brug E. Ciprofloxacin-impregnated poly-L-lactic acid drug carrier. New aspects of a resorbable drug delivery system in local antimicrobial treatment of bone infections. Arch Orthop Trauma Surg. 1992;112(1):33-35.

8. Suchý T, Šupová M, Klapková E, et al. The release kinetics, antimicrobial activity and cytocompatibility of differently prepared collagen/hydroxyapatite/vancomycin layers: microstructure vs. nanostructure. Eur J Pharm Sci. 2017;100: 219-229.

9. Nishimura J, Nakajima K, Souma Y, et al. The possibility of using fibrin-based collagen as an antibiotic delivery system. Surgery Today. 2013;43(2):185-190.

10. Rapetto F, Bruno VD, Guida G, Marsico R, Chivasso P, Zebele C. Gentamicin-impregnated collagen sponge: effectiveness in preventing sternal wound infection in high-risk cardiac surgery. Drug Target Insights. 2016;10(Suppl.1):9-13.

11. Mader JT, Calhoun J, Cobos J. In vitro evaluation of antibiotic diffusion from antibiotic-impregnated biodegradable beads and polymethylmethacrylate beads. Antimicrob Agents Chemother. 1997;41(2):415-418.

12. Holt JG, Krieg NR, Sneath PHA, Staley JT, Williams ST (eds): Bergey's manual of determinative bacteriology. 9th ed. Baltimore: Lippincott, Williams \& Wilkins; 2000.

13. UTHSCSA ImageTool 2.0, The University of Texas Health Science Center in San Antonio, ${ }^{\circ} 1995-1996$. Available at http://ddsdx.uthscsa.edu (accessed 03 Jan 2020)

14. EUCAST Clinical breakpoints - bacteria (v 9.0) (1 Jan, 2019). Available at http://www.eucast.org/clinical_breakpoints (accessed 03 Jan 2020). 
15. Bungau S, Tit DM, Fodor K, et al. Aspects regarding the pharmaceutical waste management in Romania. Sustainability. 2018;10(8):2788.

16. Dumitru N, Cocolos A, Caragheorgheopol A, et al. Collagen - the ultrastructural element of the bone matrix. Rev Chim (Bucharest). 2018;69(7):1706-1709.

17. Nishimura J, Costa Almeida CE, Reis L, Carvalho L, Costa Almeida CM. Collagen implant with gentamicin sulphate reduces surgical site infection in vascular surgery: A prospective cohort study. Int J Surg. 2014;12(10):1100-1104.

18. Abdel-Daim MM, Ahmed A, Ijaz J, et al. Influence of Spirulina platensis and ascorbic acid on amikacin-induced nephrotoxicity in rabbits. Environmental Science and Pollution Research. 2019;26(8):8080-8086. 